\title{
Contribuições da contação de histórias na educação infantil: narrativas e reflexões
}

\section{Contributions of storytelling in early childhood education: narratives and} reflections

\author{
Jannaina Calixto de Lima ${ }^{1}$, Vitor Gomes*1 .
}

\section{RESUMO}

Trata-se de artigo que possui como objetivo a apresentação da contação de histórias como contribuição às práticas docentes na educação infantil. Metodologicamente possui inspiração de uma fenomenologia existencial aplicada a educação. Aponta que o uso desta prática possibilita momentos potentes nesta etapa de ensino, provocando assim, percepções e indicações de caminhos reflexivos para a solução dificuldades vivenciadas no dia-a-dia pelo professor. Como considerações finais defende a necessidade de reflexão e reinvenção do saber/fazer pedagógico adicionando a contação de histórias para uma práxis docente que una o lúdico ao ensino e aprendizagem.

Palavras-chave: Contação de histórias; Educação infantil; Práticas docentes.

\begin{abstract}
This article aims to present storytelling as a contribution to teaching practices in early childhood education. Methodologically, it is inspired by an existential phenomenology applied to education. It points out that the use of this practice enables powerful moments in this teaching stage, thus provoking perceptions and indications of reflective paths to solve the difficulties experienced in the day-to-day by the teacher. As final considerations, he defends the need for reflection and reinvention of pedagogical knowledge/doing, adding storytelling to a teaching praxis that unites playfulness to teaching and learning.
\end{abstract}

Keywords: Storytelling; Child education; Teaching practices.

\footnotetext{
${ }^{1}$ Universidade Federal do Espírito Santo. *E-mail: vitor.gomes@ufes.br
} 


\section{INTRODUÇÃO}

Viver em sociedade provoca inúmeras reflexões sobre os entrelaçamentos com o outro e consigo mesmo. Diante das imensuráveis transformações com a denominada sociedade da informação, modos de vida são alterados pelo consumo digital de produtos e notícias em ritmo frenético.

Se no passado, ler um jornal impresso era suficiente. Hoje, para alguns, significa uma defasagem de informação. Assim, por meios digitais somos induzidos ao consumo de notícias praticamente em tempo real.

Dentro do ambiente educacional, estas questões causam preocupação. Uma vez que certos alunos desvelam comportamentos de alienação tecnológica e, com isto, evidenciam distanciamentos das interações humanas reais, fato que desafia professores em sala-de-aula, local em que, por vezes, o celular ocupa o lugar da interação com os colegas.

Diante disso, é necessário o emprego de práticas que favoreçam a interação e a aprendizagem desses sujeitos. Por essa via, compreendemos a contação de histórias como possibilidade de imersão teórica/lúdica numa contramão, contrabalanceamento e/ou flexibilização da lógica atual de virtualização em que há vício tecnológico, velocidade no consumo das informações e insuficiência de imersão significativa nestas.

Walter Benjamim, na obra Magia e técnica, arte e política, alerta para o fato de que essa prática de narrativa está fadada ao desaparecimento, em função da reprodução da informação pela indústria cultural. Se, no século passado, sem ter vivenciado o surgimento das tecnologias da informação e os avanços por ela gerados, essa era sua sentença, esse risco se torna muito mais forte hoje, pois, como destaca o teórico:

[...] na realidade, esse processo, que expulsa gradualmente a narrativa da esfera do discurso vivo e ao mesmo tempo dá uma beleza ao que está desaparecendo, tem se desenvolvido concomitantemente com toda uma evolução secular das forças produtivas (BENJAMIN, 1994, p. 201).

Contudo, em sua defesa, expressa que a oralidade tem o poder de atravessar muros, irromper, ir além, levando os conhecimentos trazidos por aqueles que viajam pelo mundo, como o comerciante retratado em sua obra, pois "quem viaja tem muito que 
contar (BENJAMIN,1994, p.198)”. Contudo, quem fica, conforme o autor, também tem muito a narrar de suas tradições.

Em concordância com o pensador, compreendemos que a contação de histórias é ferramenta capaz de promover reflexão nas práticas docentes em suas diversas vertentes. Permite o pensar imaginativo e criativo, possibiliza problematizar questões que envolvam as necessidades dos envolvidos de maneira reflexiva e imaginativa, uma vez que suscita, em seu contexto lúdico, possibilidades e estratégias de ação.

Como ressalta Moraes (2012, p. 14):

[...] desde os tempos mais longínquos o ser humano conta as suas histórias: caçadas, conquistas, encontros, desencontros, lendas, fábulas, causos, anedotas... Enfim, muita coisa vem sendo narrada a cada dia há milênios, nos mais diversos recantos da Terra, em inúmeras línguas e dialetos, por pessoas de culturas distintas, cada uma expressando uma visão de mundo própria e singular que torna a produção do texto verbalizado um evento único e original.

Essa atividade envolve memória, lembranças e estimula a oralidade. É algo que perpassa a alma, contagia, encanta, diverte e abre caminhos para pensar ao léu, ao solto, ao desprendido. Permite o acesso à imaginação, à viagem, ao conhecimento e, sobretudo, à liberdade de expressão.

Contudo, adverte Dohme (2017, p. 12):

[...] contar histórias para crianças até que é relativamente fácil. Mas exige do contador um real interesse nesse relacionamento. Mais que isso, exige respeito aos limites, às emoções e aos valores dessa criança. É preciso ainda estar disposto a ouvir atentamente. No entanto, há um obstáculo que pode tornar-se intransponível para alguns: é preciso voltar a ser criança.

Seu viés interativo concede aos envolvidos o atravessamento pela vivência e experiência com o outro. Para Larrosa (2001, p. 2): “[...] a experiência é o que nos passa, o que nos acontece, o que nos toca. Não o que se passa, não o que acontece, ou o que toca. A cada dia se passam muitas coisas, porém, ao mesmo tempo, quase nada nos acontece".

Assim, possibilitar o encontro com a contação de histórias nos espaços-tempos da educação infantil potencializa aprendizagens, que por meio do lúdico, edificam pontes 
dialógicas entre as crianças e seus docentes estimulando a criatividade, imaginação e relações positivamente afetivas entre professores e alunos, favorecendo assim, o ensino e a aprendizagem em nível da complexidade humana que nos é inerente.

Este artigo, com aproximações ensaísticas, derivado de estudo de mestrado, possui como objetivo apresentar a contação de histórias como contribuição às práticas docentes na educação infantil, evidenciando narrativas particulares e reflexões acerca de seu emprego como fomentador da resiliência, capacidade crítico-reflexiva e criatividade nas/com crianças e professores desta etapa de ensino da educação básica.

\section{CAMINHOS METODOLÓGICOS}

Este artigo possui inspiração de uma fenomenologia existencial aplicada à educação (como metodologia de pesquisa). Sua origem é derivada de nosso estudo de mestrado acerca da prática de contação de histórias cujos aspectos metodológicos fizeram uso da fenomenologia a partir de um viés educacional.

Pesquisas com essa abordagem evidenciam a natureza qualitativa vivida no cotidiano, permitindo protagonismos e aproximações do real com os sujeitos envolvidos. Para Forghieri (2002, p. 18): “a reflexão fenomenológica vai em direção ao "mundo da vida", ao mundo da vivência cotidiana imediata, no qual todos nós vivemos, temos aspirações e agimos".

Como método de pesquisa, a fenomenologia enseja a compreensão das coisas; daquilo que se apresenta aos sentidos, se manifesta e são identificadas pela percepção (MERLEAU-PONTY, 2011). Seu intuito é desvelar a essência (do que se investiga) na existência. Ou seja: no visível; contextualizado a um espaço e tempo intrinsicamente ligados à compreensão do humano e aos sentidos que se concedem as coisas (pelo pesquisador/a), vistas como fenômenos.

O método fenomenológico, embora único e com concepções basilares, possui variedades de formas de execução (FORGHIERI, 2002). Nesse sentido, realizamos imersões no fenômeno apresentando narrativas acerca das vivências e a prática da 
contação de histórias, bem como, proposições de seu uso na educação infantil utilizando concepções de Walter Benjamim e outros/as teóricos/as.

Essa dinâmica foi constituída pelos conceitos de envolvimento existencial e distanciamento reflexivo do livro: Psicologia fenomenológica: fundamento, método e pesquisas, de autoria da psicóloga e educadora Yolanda Cintrão Forghieri, que compreendemos como uma das pioneiras no Brasil na construção de um método fenomenológico aplicado à educação.

O envolvimento existencial é imersão existencial no fenômeno pelo/a pesquisador/a, buscando sua descrição literal para sua posterior compreensão. Esses passos procedimentais contribuem para a experienciação do fenômeno tal como ele se mostra no que é visível, na existência. Para isto, Forghieri (2002, p. 60) pontua:

[...] o pesquisador precisa iniciar seu trabalho procurando sair de sua atitude intelectualizada para se soltar ao fluir de sua própria vivência, nela penetrando de modo espontâneo e profundo, para deixar surgir a intuição, percepção, sentimentos e sensações que brotam numa totalidade, proporcionando-lhe uma compreensão global, intuitiva, préreflexiva, dessa vivência.

Já o distanciamento reflexivo, trata-se de uma compreensão do fenômeno a partir dos conhecimentos científicos. Aqui, o/a pesquisador/a realizará análises em interrelação com o estado do conhecimento. Neste artigo, esses momentos são imbricados e alimentados pelas narrativas e associações teóricas abordadas nos itens: Trajetória com a contação de histórias: o lugar que habito e Reflexões sobre a contação de histórias na educação infantil. Nestes apropriamo-nos da defesa que Forghieri realiza sobre a importância da reflexão; da busca do que é vivido e experienciado na existência humana.

Para ressalta a autora, “[...] retornar à experiência vivida e sobre ela fazer uma profunda reflexão que permita chegar à essência do conhecimento, ou ao modo como este se constitui no próprio existir humano" (FORGHIERI, 2002, p. 59).

Desta forma, partimos da experiência do vivido, narradas a partir de memórias afetivas interrelacionadas com as concepções teóricas. Esperando apresentar contribuições desta prática dentro de um lugar, espaço e tempo de sujeitos imbricados afetivamente e intelectualmente com seu uso. 


\section{TRAJETÓRIA COM A CONTAÇÃO DE HISTÓRIAS: O LUGAR QUE HABITO}

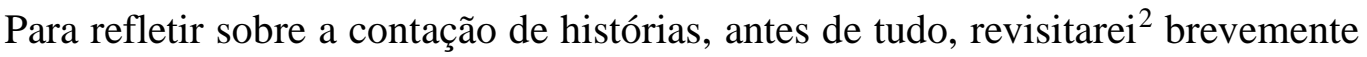
memórias, apresentando narrativas que estão latentes em minha trajetória, vivida em boa parte, no interior de Minas Gerais, nas rodas de histórias ao lado das enormes fogueiras e de muita conversa.

Compreendo que partilhar as lembranças trazem à tona minhas representações sociais acerca de tais práticas (MOSCOVICI, 2012) apresentando uma experiência eidética de sentido, que compartilha o vivenciado (HOLANDA, 2003) e evidencia o que nos afeta e move como pesquisadora. Afinal, quem fala de um tema se expressa de um lugar, certo?

Lembro-me das rodas de conversas, muitas vezes à luz de lamparina ou da fogueira que tanto me fascinavam. Os contos, os causos, as prozas, as contações de histórias que instigavam minha insaciedade (diante do prazer despertado pelo lúdico) expressa em súplicas do tipo: Conta outra vez?

Rememorando aquela época, concluo que ali me foi plantada uma das sementes que no futuro germinariam e me tornariam uma contadora de histórias. Afinal, "sem o outro não temos a capacidade de nos tornarmos eu (BERNADINI; MAIA, 2009, p.7)".

Essas vivências deixaram marcas que me apontaram caminhos. Por essa via, compreendo que "a representação social, expressa uma espécie de saber prático de como, os sujeitos em processos de interação com outros, sentem, assimilam, aprendem e interpretam o mundo (NOVAES; ORNELLAS; ENS, 2017, p.1003)”.

Dessa forma, minha forma de interiorização e aprendizagem dessas experiências me induziram a escolha da profissão: professora. Fato que, diante das vivências com a contação de histórias, levaram-me a realização de graduação em pedagogia e especialização em educação infantil, possibilitando compreensão sobre o que experienciei

\footnotetext{
${ }^{2}$ Utilizarei o Eu (primeira pessoa do singular) com intuito de apresentar a imersão existencial nas memórias e sentimentos que me constituem diante ao que descrevo (a primeira autora).
} 
na infância: a oralidade, os repertórios linguísticos, a imaginação, o lúdico (NOVAES; ORNELLAS; ENS, 2017).

Num exercício de memória para entendimento de como surgiu a ligação afetiva inicial com a contação de histórias, surgem lembranças dos primeiros momentos de leituras vividas em minha infância.

Em imagem mental, visualizo-me deitada no canto da cama de minha avó materna, local em que todas as noites ouvia uma história, um conto, um causo. E, ao perguntá-la sobre como sabia tanta coisa, dizia: De ouvir meus pais contarem.

Em concordância com Novaes (2015, p.333): “A ideia de constituição de si por meio da interação com o outro evidencia a necessidade de reconhecimento das dimensões de afeto, sentido, significado e valor na produção do conhecimento". Neste sentido, compreendo que tais aspectos edificaram minha constituição como pessoa e incitaram para o futuro uso da prática de contação de histórias.

Desta forma, creio nos momentos vivenciados na infância como pistas indicadoras do caminho que tenho trilhado. Assim, trago internamente questões retóricas do tipo: $\mathrm{O}$ que pode uma história bem contada, um conto, um causo? E o que pode uma conversa, um diálogo?

Em exercício de inferência, compreendo que esses são espaços-tempos potencializadores para desenvolver o hábito de leitura, de instigar ao conhecimento, de despertar algo que é próprio da criança: a curiosidade.

Tocada por essa experiência que me move tornei-me uma apaixonada pela contação de histórias utilizando-a nos diversos espaços profissionais. Dentre eles, como professora da educação infantil de 2004 até 2009 e coordenadora de uma equipe interdisciplinar municipal (no interior do Estado do Espírito Santo).

Tornei-me professora nas diversas etapas de ensino da educação básica, fato que permitiu-me perceber que não há idades inadequadas para vivenciar a contação de histórias. Explicita Moraes (2012, p. 40):

[...] ao narrarmos, construímos no nosso imaginário os sons, as imagens, os cheiros, os sabores e as percepções táteis relacionadas aos ambientes da mesma. Podemos entrar na casa que criamos, andar pela estrada que construímos em nossa imaginação, sentir frio, fome, 
sabores, cheiros, escutar os pássaros cantando, um grito distante, o estrondo de um trovão.

Numa mudança de ares, em 2013, depois de aprovação em concurso público municipal na grande Vitória-ES, assumo como professora das séries iniciais e, neste espaço-tempo, início aproximações, imersões e, posteriormente, oferto formações continuadas para seus docentes utilizando a contação de histórias como ferramenta potencializadora desses encontros.

Assim, a experiência como contadora de histórias tem transpassado todos os níveis em que atuo, seja na educação escolar básica, seja na educação superior, seja na pósgraduação, compreendendo-a como prática inventiva e criativa de aprendizagem.

Como a vida possui caminhos inesperados, a partir do convite pela Secretaria de Educação do município onde atuo, inicio em 2017 uma trajetória como assessora pedagógica da educação infantil adentrando nas questões administrativas/gerenciais da formação continuada de professores desta etapa de ensino.

Nessa oportunidade, pude ofertar a visibilização da prática que sempre me acompanhou em meu percurso como ser-no-mundo (HEIDEGGER, 1995). Assim, agora como assessora, inseri nas formações docentes o uso de contação de histórias.

Esses espaços-tempos de aprendizagem eram realizados em datas pré-fixadas (no calendário anual) com temas que, normalmente, eram sugeridos pelos próprios professores e pedagogos mediante consulta prévia. E assim, iniciavam as formações com a contação de histórias voltadas para cada tema, fazendo uso de materiais concretos, fantoches, literatura infantil e poemas.

Considero essas ocasiões como prazerosas e enriquecedoras das práticas docentes, cujas vivências provocaram curiosidade e imersão. Ademais, foram potencializadoras de reflexão a partir das discussões acerca da diversidade e diferença.

Nessas oportunidades, abriram-se possibilidades de vivências que remontaram à infância dos sujeitos ali presentes, ofertando à memória, seja por meio de um conto, seja num poema, seja numa música, seja numa história (narrada ou lida), evocando elucidações das variadas escolhas que realizaram até sua docência. 
Em conformidade com Coelho (1986, p. 20): “[...] passei a observar também a reação dos adultos (incluindo os idosos) em diversas ocasiões. A história faz todos sorrirem, a aula passa a ser uma divertida brincadeira - e gente grande volta a ser criança”.

No espaço-tempo de um curso de mestrado em educação, realizei estudo sobre a contação de histórias e sua contribuição para formação continuada na educação infantil. Neste sentido, destaco Freire (1996, p. 29) quando afirma: “[...] não há ensino sem pesquisa e pesquisa sem ensino. Esses fazeres se encontram um no corpo do outro. Enquanto ensino continuo buscando, reprocurando."

Por fim, as vivências nos processos escolares de formação humana vislumbradas, bem como, as experimentações da realização da pesquisa me permitiram a oportunidade de imergir, indagar e refletir sobre a formação continuada de professores(as) da educação infantil e compreender que existe uma lacuna a ser preenchida, na qual, a prática de contação de histórias "cabe como uma luva".

\section{REFLEXÕES SOBRE A CONTAÇÃO DE HISTÓRIAS NA EDUCAÇÃO INFANTIL}

Abordados os aspectos relativos às vivências espaço-temporais e a contação de histórias, em perspectiva reflexiva que se aproxima de um ensaio, auxiliados por concepções de Walter Benjamin e outros autores, evidenciaremos reflexões acerca de capacidades que essa prática pode fomentar em/com crianças na educação infantil.

Primeira etapa da educação básica, a educação infantil é constituída por conjunto de práticas para desenvolvimento integral de crianças de 0(zero) a 5 (cinco) anos de idade. Para isto, utiliza saberes culturais, artísticos, ambientais, científicos e tecnológicos produzidos pela sociedade (BRASIL, 2010).

Em favor do uso da contação de histórias nesta fase, apontamos como argumento inicial: a faixa etária das crianças, que neste espaço-tempo possuem melhor receptividade ao lúdico. Ademais, as Diretrizes Curriculares para a Educação Infantil orientam sobre a necessidade de consideração dos princípios: “[...] estéticos: da sensibilidade, da criatividade, da ludicidade e da liberdade de expressão nas diferentes manifestações 
artísticas e culturais (BRASIL, 2010, p. 16)" como norteadores das propostas pedagógicas desta modalidade.

Adicionalmente, como prática pedagógica se constitui como interessante meio para abordagem de conceitos e/ou capacidades transdisciplinares que, nesta tenra idade, seriam mais complexos de entendimento e desenvolvimento por outras vias.

Mas o que é transdisciplinaridade?

Conforme Nicolescu (1999, p.1): "transdisciplinaridade, como o prefixo "trans" indica, diz respeito ao que está, ao mesmo tempo, entre as disciplinas, através das diferentes disciplinas e além de todas as disciplinas”. Dentro disto, são inúmeros saberes que perpassam o ensino e a aprendizagem humanas reverberados na cultura de diversas sociedades. São conhecimentos ancestrais, familiares e culturais que habitam diversos espaços (escolares ou não).

Contar histórias é uma prática que perpassa gerações, proporciona momentos de comunicação, de prazer, de propagação e preservação de culturas (BENJAMIN, 1994,), bem como, possibilita a reflexão, compreensão ou diálogo sobre conflitos. É ação que potencializa o imaginário, permite a fruição de sentimentos e liberdade de expressão, possibilitando à criança distanciar-se de uma vivência adversa e desta forma, favorecer (em certos casos) sua transposição de adversidades e angústias.

Seu viés lúdico estimula e fomenta a resiliência, "capacidade humana para enfrentar, sobrepor-se e ser fortalecido ou transformado por experiências de adversidades (GROTBERG, 2005, p.20)”. Por essa via, como registra Gutfreind (2004, p. 25): “[...] os contos têm importância capital para a vida psíquica das crianças, pois imaginando, a criança pode brincar com temas próprios de sua realidade psíquica, por vezes difícil, como o amor, o medo, a rivalidade fraterna, a separação e o abandono".

Desta forma, proporciona o acesso aos medos, dores, sentimentos negativos, que, se trabalhados adequadamente pelo/a professor/a e/ou contador/a de histórias, pode proporcionar à criança crescimento e resiliência.

Para isso, frases iniciais como: era uma vez, num reino muito distante, há muito tempo atrás, num certo país, há milhares de anos, no fundo do mar e outras, abrem janelas da alma e permitem acessar lugares dantes obscuros e cheios de temores. 
Como registra Bettelheim (2003, p. 78): “[...] são inícios que sugerem que o que se segue não pertence ao aqui, e agora que nós conhecemos. Esta indefinição deliberada do início dos contos simboliza que estamos deixando o mundo concreto da realidade comum".

Contudo, no que se refere a lidar com revezes, em muitos casos, não basta apenas contar histórias isoladamente. É necessário o trabalho conjunto entre contadores/as de histórias, pedagogo/as, psicólogos/as, assistentes sociais, professores/as e outros profissionais, para que o uso dessa prática surta efeitos positivos nas crianças.

Como pontuam Tierno e Erdtmann (2017, p. 20):

[...] o contador é aquele que ordena. Mas organiza o quê? Coloca em ordem acontecimentos, experiências. Nesse sentido, o contador de histórias é aquele que ordena os acontecimentos, as experiências vividas, atribuindo um sentido ao vivido, ao experimentado.

Sendo assim, se bem empregada, como num trabalho multidisciplinar articulado, a contação de histórias favorece aos seus ouvintes distanciamento das experiências adversas, que dentro de sua dimensão lúdica, potencializa a racionalização, enfrentamento e fortalecimento psicológico e/ou de superação das memórias negativas.

Elencando outra capacidade que pode ser potencializada, a contação de histórias pode contribuir para a reflexão sobre os espaço-tempos atuais, potencializando a crítica e reflexão acerca das questões que envolvem a contemporaneidade ou vivências particulares.

Como contadora de histórias me constituo num permanente vir-a-ser derivado dos múltiplos encontros em quais realizo tal prática. Desses imbricamentos destaco ${ }^{3}$ o efeito desta atividade como fomentadora da capacidade crítica-reflexiva.

Desta forma, ao ouvir contos e/ou histórias as crianças podem ser despertadas com detalhes que as induzem a realização de analogias e reflexões singulares acerca das questões do dia-a-dia em interconexões com o vivido (QUELUZ,1984).

\footnotetext{
${ }^{3}$ A partir das interações e expressões que as crianças/professores(as) ofertam nos momentos em que essas são contadas.
} 
Nestes momentos, é comum ouvir frases das crianças do tipo: Tia: isso é igual aquilo que o moço da televisão falou ontem. Ou ainda: minha mãe é igual a essa menina da história que a senhora contou, ambas que associam aos enredos das histórias com os contextos das vivências particulares e/ou apropriação singular da realidade.

Contudo, para que tal prática seja potencialmente qualificada, é necessário que o contador/a possua sensibilidade para intercalar seu emprego com momentos de diálogo e escuta. Para isto, é necessário saber o momento de ouvir e/ou interagir com as crianças.

Por essa via, provocadas pelos seus enredos, e de acordo com a intenção deste (o contador/a), a contação de histórias se constitui como prática que pode estimular a capacidade crítico reflexiva sobre diversas temáticas que envolvem o dia-a-dia da escola, mas também a transpassa (SCHAFRANSKI, 2005), edificando estes momentos como possibilidade de reflexão e aprendizagens para a vida.

Desvelando outras possibilidades, a prática de contação de histórias potencializa a criatividade na criança, permitindo ampliar o vocabulário, os conhecimentos de mundo e de outras culturas; proporcionando o ir e vir sem se deslocar do lugar, simplesmente por uma abertura que, às vezes, vem por um sussurro, por uma música, por uma voz.

Era uma vez... e aqui pedimos perdão pela paixão e poesia, são palavras mágicas, que lançadas como um pó, que transformam o ar, a atmosfera e o ambiente, provocando sensações capazes de transportar ouvintes infantes a espaços e tempos distantes.

Esse movimento provoca deslocamentos, fazendo movimentar o pensamento infantil, ampliando sua capacidade criativa e de transcriação (CORAZZA, 2013), afastando-os das exclusivas dinâmicas de memorização e reprodução (BENJAMIN, 1994) comuns na educação infantil.

Há que se provocar mais a narrativa e não apenas reproduzir materiais didáticopedagógicos com respostas e modelos /pré-estabelecidos que funcionam como limitadores do pensamento criativo da criança.

Em sua obra O narrador, Benjamin (1994) pontua essa necessidade de explorar a narrativa como ampliação da linguagem e das experiências vividas e o valor do saber em intercambiar experiências. Essas experiências têm sido cada vez menos presentes em 
tempos atuais e urge retomá-las, para assim provocar a expansão da criatividade e reflexão crítica do viver em sociedade.

Ao narrar, ouvir, contar e recontar histórias muitas são as conexões ativadas pela memória e que reverberam em experimentações inventivas e criativas (KASTRUP, 1998), possibilitando momentos/vivências potentes e de múltiplas aprendizagens. Porém, muitas são as questões que emergem antes do uso dessa prática. Como por exemplo: O que contar e para quem contar? Onde contar e como contar? O que usar?

Muitos questionamentos nos saltam aos olhos, porém, vão se dissipando em cada história contada, em cada poema narrado, em cada causo restaurado, seja na voz suave ou exaltada, seja no silêncio entre uma palavra e outra... contar realmente é uma arte, e como tal precisa ser desenvolvida.

Assim, a prática de contação de histórias é ferramenta potente, inventiva, deflagradora de criatividade no(a) professor/a e alunos/as num processo contínuo e participativo por todos os envolvidos, em que, conforme Kastrup (1998, p. 109): “[...] os sujeitos e os mundos são inventados, criam-se formas, regularidades, estratos históricos, embora estes se conservem em constante processo de transformação". Por fím, compreendemos que sua prática propicia momentos espontâneos de reflexão e múltiplas aprendizagens que corroboram de forma sine qua non com a formação humana na educação infantil.

\section{CONSIDERAÇÕES FINAIS}

Diante das inúmeras demandas a que somos submetidos hoje, observamos a velocidade do desaparecimento de práticas orais como a contação de histórias nas relações sociais no dia-a-dia. Notamos o apreço pelo que é imediato, a necessidade de comunicação objetiva, sem aprofundamento. Tempos de resultados esperados a qualquer custo, de apreciar informações que são mais próximas à realidade vivida, distanciando-se do conhecimento que vem de longe, que perpassou outros entrelugares, outros mundos.

Desse modo, as reflexões sobre as práticas orais promovida por Walter Benjamin e outros autores sublinham a importância de explorarmos as narrativas como forma de 
expressão de sentido, de vida, de essência ${ }^{4}$ do humano em seus processos socioculturais e nas práticas educativas, pensadas e refletidas pelos professores da educação infantil como potencializadora de compreensão de suas práxis docentes.

Trazer a reflexão dessas práticas docentes, sobretudo, desta modalidade, necessita de transformações/adaptações dinâmicas compatíveis aos contextos sociais brasileiros e imbricamento com a concepção de infância deste espaço-tempo (ENS; NAGEL; BUENO, 2018).

Neste sentido, compreendemos a necessidade de reflexão e reinvenção do saber/fazer pedagógico, adicionando a contação de histórias nas práticas docentes, para assim, reverberar numa práxis pedagógica que una o lúdico ao ensino e aprendizagem, no qual se edifica um processo de duplo enriquecimento: de um lúdico com mais aprendizagem, e de uma aprendizagem com mais ludicidade.

Para isto, é necessário vontade, mas também, inquietação, criatividade e compreensão de que é mister o engajamento e sensibilidade. Seja como possibilidade de cuidado de si, seja como cuidado do outro. Uma vez que, quando inserimos o lúdico no contexto de sala-de-aula, construímos pontes de aproximação pedagógico-emocionais com nossos alunos, nas quais, podemos abordar certos conteúdos que, de uma forma tradicional, não alcançariam sua compreensão e/ou interesse.

Dimensões contextualmente exploradas na contação de histórias, nas quais, crianças, professores(as) e todos que dela participam, vivenciam a ludicidade seja na narrativa, num conto ou na leitura de um livro. Ela tem o poder de explorar a criatividade, a sensibilidade, contribuindo com experimentações de diversas práticas de manifestações culturais.

Por fim, para que o sujeito construa sua identidade, é mister a utilização de práticas pedagógicas capazes de proporcionar experiências significativas nesta modalidade. Este é o espaço-tempo propício para inserção da contação de histórias e sua exploração da

\footnotetext{
${ }^{4}$ Nos referimos a essência num sentido fenomenológico do existencialismo. Ou seja: como aquilo que é histórico, contextual e delimitado pela apreensão perceptiva de quem a investiga. Trata-se da essência que se apresenta na existência e que é visualizada por meio de uma fenomenologia da percepção (MERLEAUPONTY, 2011).
} 
imaginação, fantasia, do pensar individual e coletivo, tornando vivas narrativas e memórias que potencializam a pluralidade de ser e estar no mundo.

\section{REFERÊNCIAS}

BENJAMIM, W. Magia e técnica, arte e política. São Paulo: Brasiliense, 1994.

BERNADINI, C. H; MAIA H. Representações sociais de professores sobre o bullying. Nuances: estudos sobre Educação, v. 16, n. 17, p. 169-182, 2009.

BETTELHEIM, B. A psicanálise dos contos de fadas. $17^{\mathrm{a}}$.ed. Rio de Janeiro: Paz e Terra, 2003.

BRASIL. Ministério da educação. Secretaria da educação básica. Diretrizes curriculares nacionais para a educação infantil. Secretaria da educação básica. Brasília: MEC, SEB, 2010.

COELHO, B. Contar histórias - uma arte sem idade. São Paulo: Ática, 1986.

CORAZZA, S. M. O que se transcria em educação. Porto Alegre-RS: Doisa, 2013.

DOHME, V. D.. Técnicas para contar histórias: Um guia para desenvolver habilidades e obter sucesso na apresentação de uma história. 3. ed. Petrópolis-RJ: Vozes, 2017.

ENS, R. T; NAGEL, J. S. O; BUENO, E. D. L. Educação infantil e currículo: Uma Análise da proposta da rede municipal de Curitiba/PR. Série-Estudos, v. 23, n. 49, p. 97-117, 2018. Disponível em:< https://www.serie-estudos.ucdb.br/serieestudos/article/view/1136>. Acesso: em 04 maio 2020.

FORGHIERI, Y. C. Psicologia fenomenológica: fundamentos, método e pesquisas. São Paulo: Pioneira, 2002.

FREIRE, P. Pedagogia da autonomia: saberes necessários à prática educativa. 35 . ed. São Paulo: Paz e Terra. 1996.

GROTBERG, E. H. Introdução: novas tendências em resiliência. In: MELILLO, A; OJEDA, E. N. S. (org) Resiliência: descobrindo as próprias fortalezas. Porto Alegre: ARTMED, 2005.

GUTFREIND, C. Contos e desenvolvimento psíquico. Viver Mente \& Cérebro. Novembro de 2004.

HEIDEGGER, M. Ser e tempo. Petrópolis/RJ: Vozes, 1995. Parte I e II.

HOLANDA, A. F. Pesquisa fenomenológica e psicologia eidética: elementos para um entendimento metodológico. In: BRUNS, M A. T; HOLANDA, A. F. (Org.). Psicologia e fenomenologia: reflexões e perspectivas. Campinas: Alínea, 2003. p. 41-64. 
KASTRUP, V. A cognição contemporânea e a aprendizagem inventiva. Arquivos Brasileiros de Psicologia, v. 49, s/r, p. 108-122, 1998. Disponível em:< https://revistadesvioblog.files.wordpress.com/2018/08/kastrup_v-cognicao-artigo2.pdf >. Acesso em 11 abr. 2020.

MERLEAU-PONTY, M. Fenomenologia da percepção. São Paulo: Martins Fontes, 2011.

MORAES, F. Contar histórias: a arte de brincar com as palavras. Petrópolis, RJ: Vozes, 2012.

MOSCOVICI, Srge. A psicanálise, sua imagem e seu público. Petrópolis: Vozes, 2012.

NICOLESCU, B. Um novo tipo de conhecimento - transdisciplinaridade. In: I ENCONTRO CATALISADOR DO CETRANS - Escola do Futuro. São Paulo: USP, 1999, p. 1-10. Disponível em: http://www.ufrrj.br/leptrans/arquivos/conhecimento.pdf> Acesso em: 31 ago.2021.

NOVAES, A. Subjetividade social docente: elementos para um debate sobre "políticas de subjetividade". Cad. Pesqui., v. 45, n. 156, p. 328-343, 2015. Disponível em <http://www.scielo.br/scielo.php?script=sci_arttext\&pid=S010015742015000200328\&lng=pt\&nrm=iso>. Acesso: em 04 maio 2020.

NOVAES, A; ORNELLAS, M. L; ENS, R. T. Convergências teóricas em representações sociais e seu aporte para o estudo de políticas docentes Rev. Diálogo Educ., v. 17, n. 53, p. 999-1015, 2017. Disponível em:< http://dx.doi.org/10.7213/1981-416X.17.053.AO14>. Acesso em 04 de maio 2020 .

QUELUZ, A. G. A pré-escola centrada na criança: uma influência de Carl R. Rogers. São Paulo: Pioneira, 1984.

SCHAFRANSKI, M. D. A educação e as transformações da sociedade. UEPG Humanit. Sci., Appl. Soc. Sci., Linguist., Lett. Arts, v.13, n.2, p.101-112, 2005. TIERNO, G; ERDTMANN, L. L. (Orgs.). Narra-te cidade: pensamentos sobre a arte de contar histórias hoje. São Paulo: A Casa Tombada, 2017. 